\title{
MODERNIZAÇÃO DA AGRICULTURA VERSUS DESENVOLVIMENTO TERRITORIAL: REFLEXÕES SOBRE A ATIVIDADE MANDIOQUEIRA NO AGRESTE POTIGUAR
}

\author{
D. S. C. de O. Salvador \\ ${ }^{1}$ Departamento de Geografia da Universidade Federal do Rio Grande do Norte - CERES
}

Artigo submetido em dezembro/2010 e aceito em abril/2011

\begin{abstract}
RESUMO
O presente trabalho analisa a contribuição da modernização da atividade mandioqueira para o desenvolvimento territorial do Agreste Potiguar. Para isso, as discussões são alçadas com uma reflexão crítica sobre o perverso processo de modernização da agricultura brasileira e, especificamente, da perversa modernização da atividade mandioqueira no Agreste Potiguar. Após a realização de pesquisa bibliográfica e de pesquisa de campo, a qual foi desencadeada, numa perspectiva qualitativa, entre os anos de 2008 e 2010, constituindo-se em observações feitas no espaço agrícola dos municípios do Agreste Potiguar e em entrevistas realizadas junto a produtores de mandioca, proprietários e trabalhadores de casas ou de indústrias de farinha do referido território, chegamos à conclusão de que a modernização da agricultura no Brasil, propagadora de elementos ditos "novos", é um processo que não pode ser considerado como sinônimo de desenvolvimento, pois gera e/ou intensifica graves problemáticas que perpassam histórica e estruturalmente a sociedade nacional. Isso também pode ser afirmado no tocante à modernização da atividade mandioqueira no Agreste Potiguar.
\end{abstract}

PALAVRAS-CHAVE: Modernização da agricultura. Desenvolvimento Territorial. Atividade mandioqueira. Agreste Potiguar.

\section{MODERNIZACIÓN DE LA AGRICULTURA CONTRA DESARROLLO TERRITORIAL: REFLEXIONES ACERCA DE LA ACTIVIDAD MANDIOQUEIRA EN EL AGRESTE POTIGUAR}

\section{RESUMEN}

El actual trabajo analiza la contribución de la modernización de la actividad mandioquera para el desarrollo territorial del Agreste Potiguar. Para esto, las discusiones son fundamentadas con una reflexión crítica en el proceso perverso de la modernización de la agricultura brasileña e, específicamente, de la modernización perversa de la actividad mandioquera en el Agreste Potiguar. Después de la realización de la investigación bibliográfica y de la investigación del campo, que fue desarrollada, en una perspectiva cualitativa, entre los años de 2008 y 2010, consistiendo en las observaciones hechas en el espacio agrícola de las ciudades del Agreste Potiguar y en las entrevistas realizadas con productores de la yuca, de propietarios y de trabajadores de casas o industrias de harina del territorio relacionado, llegamos la conclusión que la modernización de la agricultura en el Brasil, propagandista de los elementos dichos "nuevos", es un proceso que no se puede considerar como sinónimo del desarrollo, pues tanto genera e intensifica problemáticas serias que traspasan histórico y 
estructuralmente la sociedad nacional. Esto también se puede afirmar en el respecto a la modernización de la actividad mandioquera del Agreste Potiguar.

PALAVRAS-CHAVE: Modernización de la agricultura. Desarrollo territorial. Actividad Mandioquera. Agreste Potiguar. 


\section{MODERNIZAÇÃO DA AGRICULTURA VERSUS DESENVOLVIMENTO TERRITORIAL: REFLEXÕES SOBRE A ATIVIDADE MANDIOQUEIRA NO AGRESTE POTIGUAR}

\section{INICIANDO AS DISCUSSÕES}

Neste trabalho, analisamos a contribuição da modernização da atividade mandioqueira para o desenvolvimento territorial do Agreste Potiguar (figura 01). Para isso, as discussões são alçadas com uma reflexão crítica sobre o perverso processo de modernização da agricultura brasileira e, especificamente, da perversa modernização da atividade mandioqueira no Agreste Potiguar.

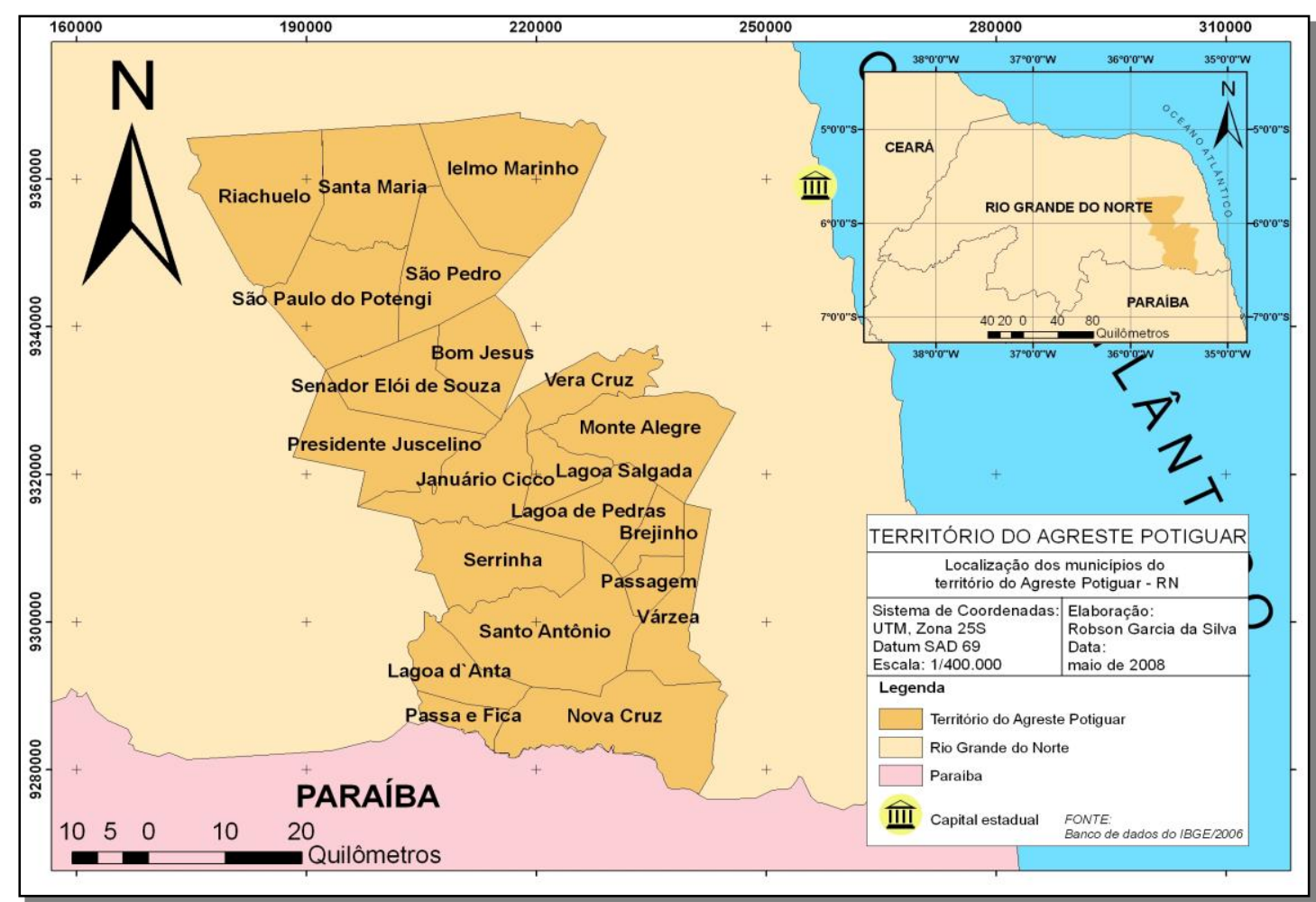

Figura 01: Agreste Potiguar no âmbito do território do Rio Grande do Norte Fonte de dados: IBGE, 2009.

Diante das abordagens realizadas, chegamos à consideração de que a modernização da agricultura no Brasil, propagadora de elementos ditos "novos", é um processo que não pode ser considerado como sinônimo de desenvolvimento, pois gera e/ou intensifica graves problemáticas que perpassam histórica e estruturalmente a sociedade nacional. Isso também pode ser afirmado no tocante à modernização da atividade mandioqueira no Agreste Potiguar.

É devido a esse movimento contraditório, em que processos de modernização são geradores e/ou intensificadores de "velhas estruturas" sociais, que explicitamos no início do presente artigo os pensamentos de Caio Prado Júnior e José de Souza Martins, que nos levam a refletir sobre a retrógrada e perversa modernização da agricultura brasileira e da mandiocultura no Agreste Potiguar, processos "dinâmicos", mas que proporcionam a permanência de "velhas" problemáticas sociais. 


\section{O PERVERSO PROCESSO DE MODERNIZAÇÃO DA AGRICULTURA BRASILEIRA}

A modernização da agricultura nacional é um processo que vem ocorrendo de maneira seletiva, excludente e parcial. Essa modernização não atinge todos os territórios e as lavouras da mesma maneira, nem com a mesma intensidade, e, dessa maneira, os agentes hegemônicos do capital privilegiam os territórios e as lavouras que lhes proporcionam a maior lucratividade possível. Outrossim, esse processo vem atuando na geração e na intensificação de graves problemáticas sociais que marcam o campo e rebatem nas cidades brasileiras, podendo ser, assim, qualificado de perverso.

Essa modernização ocorre fundamentada simplesmente na lógica do capitalismo, sendo comandada pelas grandes empresas que atuam com o apoio incondicional do Estado. Nessa perspectiva, a modernização da agricultura tem como características básicas: o investimento em máquinas e em insumos, para elevar ao máximo os rendimentos produtivos; a exploração intensa de mão-de-obra, visando aumentar, cada vez mais, a produtividade do trabalho; e a concentração da propriedade fundiária, tornando, assim, os trabalhadores "livres" dos meios de produção e "presos" aos ditames dos agentes hegemônicos. Dentre os intentos desse processo, não há nenhum interesse em melhorar a qualidade de vida de todos os trabalhadores. Isso é compreensível, mas não aceitável, quando se diz que os objetivos do referido processo são meramente econômicos, negligenciando totalmente a instância social.

A modernização da agricultura no Brasil é um processo intensivamente marcado pela ambivalência que perpassa a modernidade ${ }^{1}$ (OURIQUES, 2001). Os avanços técnicos, que poderiam possibilitar a melhoria da vida dos homens, acabam sendo usados em benefício apenas de alguns, tornando a vida da maioria cada vez mais precária, ou seja, marcada por graves problemas de ordem social, econômica, política, ambiental etc. Essa situação remete ao pensamento de que a máquina, que poderia libertar os homens, acaba se tornando, da maneira como é utilizada, instrumento para a escravização deles (Ibid.).

Graziano da Silva (2003) aponta alguns resultados dessa modernização perversa: intensificação da concentração fundiária, êxodo rural, superexploração dos empregados e aumento da concentração de renda nas mãos dos agentes hegemônicos. Em suma, trata-se de um processo ancorado na lógica capitalista, que necessita, desse modo, das seletividades e das exclusões. As palavras de Elias (2003, p. 336) ratificam esse pensamento, destacando a pobreza, a desigualdade regional e a degradação ambiental como alguns problemas promovidos no âmbito da modernização da agricultura nacional:

No início de um novo milênio, vive-se uma quebra dos principais paradigmas da
relação homem-natureza e reforçam-se os questionamentos sobre a viabilidade do
modelo de agricultura adotado no Brasil com o advento da globalização. Nenhum
outro modelo promoveu tanta pobreza, desigualdade regional e degradação
ambiental em tão pouco tempo, provocando uma crise de várias magnitudes, no
campo e nas cidades, que mostra a associação entre crescimento econômico e
deterioração da situação social e ambiental, com o agravamento das contradições.

A forma como vem sendo desencadeada a modernização da agricultura brasileira faz com que o pequeno proprietário seja marcado por uma situação precária de vida, sem ter acesso, de maneira eficaz, a serviços essenciais, como educação, saúde etc. Pessoa (2003, p. 17), ao

\footnotetext{
${ }^{1}$ Entendemos que a modernidade seja a denominação dada ao atual estágio do sistema capitalista, no qual há a generalização da lógica da mais-valia em âmbito mundial.
} 
estudar a agricultura familiar no atual contexto, revela alguns motivos que explicam o fato de esses proprietários viverem nessa situação, por meio das seguintes palavras:

essa precariedade é agravada pelo tamanho reduzido dos seus estabelecimentos e má qualidade dos solos empregados na agricultura familiar, caracterizado por arriscadas condições climáticas, ausência de direitos mínimos sociais, ausência de infraestrutura produtiva, e dificuldade de acesso aos mercados [...].

Diante dessas considerações, defendemos que existe a necessidade premente de se buscar e/ou investir em outro(s) modelo(s) de modernização da agricultura no Brasil, que seja(m) alicerçado(s) no bem-estar social coletivo e não nos interesses do mercado. Para isso, são fundamentais mudanças estruturais, visando ao desencadear de outra globalização, calcada na instância social e não nos objetivos hegemônicos do mercado ${ }^{2}$ (SANTOS, 2003; ELIAS, 2007, 2003). No âmbito dessa proposição, especificamente em relação ao campo brasileiro, dizemos, coadunando com Andrade (2004), ser urgente o estabelecimento de uma política agrária no país, comprometida com a totalidade da sociedade e não apenas com um pequeno grupo formado por agentes do capital dominante. Essa política deve privilegiar a democratização do acesso à propriedade da terra, ao crédito agrícola, à assistência técnicoagronômica, bem como a organização da comercialização da produção em sistema de cooperativas (ANDRADE, 1979). Frisamos que a associação dos produtores em cooperativas não pode ter como fundamento maior o domínio do crédito e do comércio. $O$ pilar fundamental dessa associação deve ser a melhoria da qualidade de vida de todos os produtores. Caso contrário, essa associação servirá apenas para reforçar o contexto capitalista, que vem precarizando a situação de vida da maioria dos produtores (KAUTSKY, 1980).

Pode parecer espantoso ou até mesmo petulante o fato de defendermos a necessidade de se buscar e/ou de se investir em outra(s) modernização(s) da agricultura no Brasil, rompendo com a atual estrutura que marca o país, calcada nas perversidades. Ao fazermos essa defesa, diferimos das concepções de alguns autores, como Graziano da Silva (2004), que defendem que o caminho não é romper com o sistema vigente, mas sim adaptar-se ao mesmo e, assim, buscar uma melhoria da própria vida, seguindo o preceito da individualidade. Outros autores, como Lucena (2000), que estudou o papel da agricultura no crescimento econômico brasileiro, defendem a intensificação do atual processo de modernização, devido a esse gerar capitais para o agronegócio instalado no país e voltado completamente ao mercado e aos preceitos externos.

Discordamos desses pensamentos e acreditamos ser pertinente propor mudanças estruturais, alicerçadas na coletividade. Assumimos essa postura concordando com a concepção de Peet (2007), de que um humanista que comungue com a teoria crítica na modernidade deve ter uma atitude contra-hegemônica, propondo e/ou imaginando outro sistema em que o

\footnotetext{
${ }^{2}$ Há autores, como Graziano da Silva (2003), que propõem, como uma solução para os problemas gerados e/ou intensificados pela modernização da agricultura brasileira, a maior integração dos camponeses (pequenos proprietários) à economia global (agronegócio). Essa maior integração seria possível por meio de um programa global de desenvolvimento rural, o qual teria como objetivo urbanizar o campo, combinando políticas sociais compensatórias e políticas produtivistas, evitando, assim, a eliminação dos pequenos proprietários do cenário agrícola nacional (Ibid.). Ao contrário desse pensamento, acreditamos que investir simplesmente numa maior integração (entenda-se subordinação) dos pequenos proprietários às premissas dominantes do capital não seja um caminho alternativo ao processo de modernização que hora é colocado em tela. Pelo contrário, essa integração (subordinação) já é real, explicitando-se inclusive na realidade do Agreste Potiguar. Destarte, acreditamos ser necessário implementar outro modelo de modernização da agricultura, diferente daquele que é expressado no momento atual, sendo esse outro modelo calcado não em perversidades sociais, mas sim no bem-estar de todos. A implementação desse modelo exige rupturas com o processo atual, e não maiores adaptações e/ou integrações (subordinações).
} 
desenvolvimento, na plenitude da palavra, isto é, abarcador de toda a sociedade, seja o pilar fundamental. Vejamos as palavras do autor:

[...] quero dizer que a teoria crítica moderna tem de assumir uma postura contra-
hegemônica, que os intelectuais deveriam tornar-se contra-especialistas, mais
altamente treinados do que seus inimigos, e com um maior comprometimento para
com ideais mais nobres. Assim, permitam-me dizer [...], economia,
desenvolvimento, relações rurais-urbanas devem ser repensadas sob um imaginário
econômico diferente se quisermos ter um mundo com justiça social. [...] Precisamos
fazer um novo imaginário de desenvolvimento, no qual usemos nossos momentos
mais criativos para pensar diferentemente. Precisamos de uma revolução nas idéias
tanto quanto na prática. Critiquem tudo, mas convertam crítica em proposta
positiva... Esse é o credo crítico moderno (Ibid., p. 36 ).

Outra(s) modernização(ões) da agricultura deve(m) ter como um de seus fundamentos o bemestar dos trabalhadores. Caso contrário, o processo de modernização prosseguirá sendo excludente, favorecendo uma minoria em detrimento das necessidades e dos anseios da maioria, isto é, dos trabalhadores, dos pobres. Isso também é dito, de outra maneira, por Paulino (2006, p. 17): “[...] outro modelo de agricultura é possível, e [...] poderá ser associado a desenvolvimento se for includente, parcimonioso para com os bens da natureza e generoso para com os seres humanos e demais espécies vivas do planeta". Dito isso, é necessário explicitarmos o que se entende por desenvolvimento.

Não devemos tomar os conceitos crescimento e desenvolvimento como sinônimos. De acordo com Andrade (1995), este é muito mais abrangente do que aquele, envolvendo não só o crescimento da renda, mas também sua melhor distribuição, com a significativa melhoria das condições de vida da população em sua totalidade. Da mesma forma, Souza (1997) defende que considerar desenvolvimento e crescimento como sinônimos é uma impropriedade e um equívoco, devido àquele se referir a "fins" (metas revolucionárias que visam transformar o sistema vigente) e não meramente a "meios" (formas de perpetuar o contexto atual, no qual há o privilégio dos interesses dos agentes hegemônicos), diferentemente deste.

Seguindo o mesmo intento, podemos destacar as concepções filosóficas de Sartre (1978), quando nos ensina que o progresso (sinônimo de crescimento) é apenas um melhoramento que pode ser para alguns e não para todos. Diferentemente disto, o desenvolvimento é o alcance da liberdade real de todos, com o cessamento do trabalho imposto, das desigualdades e da escassez para a maioria (Ibid.). Arendt (2006), seguindo a mesma lógica de pensamento, afirma que o progresso ocorre de maneira catastrófica e põe em cheque a liberdade (o desenvolvimento) dos homens. Desse modo, asseveramos novamente que não podemos, em hipótese alguma, considerar crescimento e desenvolvimento como processos sinônimos.

Outrossim, Martins (2002), ao estudar problemas sociais que marcam o território brasileiro no início do século XXI, coloca que a questão do desenvolvimento é muito mais social do que econômica, diferentemente do crescimento. Hespanhol (2007) coaduna com esse pensamento, afirmando que o desenvolvimento é um processo marcado pelo crescimento econômico com respeito aos recursos ambientais e com a melhoria da qualidade de vida da população. Com essa concepção, esse autor assegura que no Brasil não há, até o presente momento, uma política efetiva de desenvolvimento do campo. O que existe são ações perversas que favorecem uma minoria em detrimento das necessidades e dos anseios da maioria da população rural, que vive em situação precária. 
Peet (2007) também frisa que o crescimento econômico não reduz a pobreza, especialmente quando este segue a lógica neoliberal. $\mathrm{O}$ autor prossegue afirmando, inclusive, que, sob a tutela do neoliberalismo (capitalismo), as políticas ditas de desenvolvimento tomam a forma de uma ideologia ${ }^{3}$, sendo parte de uma hegemonia ${ }^{4}$, de um discurso político ${ }^{5}$, de um imaginário ${ }^{6}$. Em outras palavras, diz-se que o desenvolvimento é um belo princípio social, sendo corrompido pelo sistema econômico vigente (Ibid.).

Nas palavras de Martins (2002), o modelo de crescimento firmado no mundo capitalista leva extremos de progresso tecnológico e bem-estar para apenas alguns segmentos sociais, e extremos de privação, pobreza e marginalização social para a maioria da sociedade. Desse modo, pode-se dizer, de acordo com o autor citado, que o sistema econômico vigente é um modelo de antidesenvolvimento, na medida em que privilegia a instância econômica em detrimento de todas as outras. Vejamos as palavras do autor:

é difícil reconhecer que haja desenvolvimento quando seus benefícios se acumulam longe da massa da população. Como é difícil reconhecer a legitimidade de um modelo de desenvolvimento que exclui legiões de seres humanos das oportunidades de participação não só nos frutos da riqueza, mas até mesmo na produção da riqueza (Ibid., p. 10).

Diante desse pensamento, com o qual acedemos, afirmamos, juntamente com Montenegro Gómez (2007), que no sistema capitalista dificilmente se pode alcançar o processo de desenvolvimento. O máximo que se pode conseguir nesse sistema é o enriquecimento de uma

\footnotetext{
3 A ideologia é compreendida por Peet (2007, p. 23) como a “[...] produção e disseminação de idéias principalmente por parte do Estado e seu aparato burocrático, que apóia e legitima a ordem social dominante [...]. Quer dizer, as idéias por trás das práticas institucionais, tais como elaborar e implementar políticas, não são concebidas de forma neutra, como finge a ciência, nem são elas pensadas no interesse de todos, como espera o humanismo moderno, mas, ao invés disso, políticas são feitas para servir aos interesses político-econômicos dominantes. Na teoria marxista, esses interesses são os das pessoas ricas da sociedade, poderosas porque possuem capital, definido como a propriedade da riqueza produtiva pelos acionistas e altos escalões de companhias e corporações".
}

\begin{abstract}
${ }^{4}$ Sobre a hegemonia, Peet (2007) segue as concepções de Gramsci e Althusser, os quais se fundamentam em Marx, afirmando ser esta a "[...] produção cultural de sistemas inteiros de valores, atitudes, crenças e moralidade que dão suporte para a ordem social existente e o modo de vida prescrito. [...] um princípio organizador difundido através da socialização, como senso comum em cada aspecto da vida diária" (Id., p. 25, destaque do autor). Peet (Ibid.) ainda destaca que toda hegemonia pode ser contestada por meio de uma contra-hegemonia, como parte da luta de classes. Ancorado nos ensinamentos de Gramsci, ele defende que essa contestação deve ser pensada por intelectuais e ativistas e posta em tela nos momentos de crises estruturais, quando as mudanças são bem-vindas pela maioria das pessoas em função de "[...] o capital, em sua crise estrutural, evidenciar os limites de seu projeto civilizatório" (THOMAZ JÚNIOR, 2008, p. 338).
\end{abstract}

${ }^{5}$ Os discursos são utilizados pelos agentes dominantes como instrumentos de poder, com o escopo de convencer a maioria das pessoas de que tudo está indo bem ou pode melhorar breve e facilmente (PEET, 2007). Sendo um instrumento de poder, o discurso é compreendido por esses agentes como uma mercadoria, sendo pensado para ser vendido ou para conquistar algo rentoso para os mesmos.

${ }^{6}$ Acerca dos imaginários, Peet (Ibid., p. 28) declara que são "[...] formas coletivas de consciência estruturadas por ambientes sociais específicos. Imaginários assumem formas classistas e regionais, quer dizer, a imaginação usa materiais (imagens, memórias, experiências) do que é familiar para projetar [...] versões teóricas do conhecido. Todavia, apesar de ta estrutura, a palavra imaginário claramente implica interpretação imaginativa e criatividade - projetar interpretações dentro do pouco conhecido -, tanto que imaginários sociais são fontes vitais de dinâmicas tanto transformacionais quanto reprodutivas. Assim, o reino do imaginário tem de ser visto como repleto de tensões, entre lógicas visionárias e lógicas mais fundamentadas, entre a sabedoria recebida e as novas interpretações, entre crenças fundamentais e formas práticas de consciência, entre modos alternativos de conhecimento e modos diferentes de imaginar" (destaque do autor). 
minoria à custa da grande maioria da sociedade. Isso em função de o capitalismo ter como alicerce o fortalecimento das desigualdades e das contradições que marcam a realidade mundial. Novamente, tomamos de empréstimo as palavras de Martins (2002, p. 11): “[...] o capitalismo que se expande à custa da redução sem limites dos custos do trabalho, debitando na conta do trabalhador e dos pobres o preço do progresso sem ética nem princípios, privatiza ganhos nesse caso injustos e socializa perdas, crises e problemas sociais".

Assim sendo, destacamos que o desenvolvimento não deve ser compreendido apenas como satisfação econômica ${ }^{7}$ (SOUZA, 2005). O desenvolvimento que possibilita a satisfação das necessidades humanas inclui outras instâncias, além da econômica, como a cultural e a política. Igualmente, Couto (2007) afirma que o discurso imediatista nos faz acreditar, por meio da propagação de ideologias falaciosas, que o crescimento econômico seja sinônimo de desenvolvimento, e vice-versa. Porém, deve-se ter a consciência de que "o crescimento econômico enquanto impulsionador do desenvolvimento social está longe de diminuir as desigualdades sociais" (Ibid., p. 15).

Nessa mesma linha de pensamento, a concepção de Sen (2000), que parece ser influenciada pelos pensamentos filosóficos de Sartre (1978) e de Arendt (2008, 2006), defende que o desenvolvimento deve ser pensado e praticado juntamente com os preceitos da liberdade. Essa concepção, da qual compartilhamos, é posta em baila a partir das seguintes palavras:

[...] o desenvolvimento pode ser visto como um processo de expansão das liberdades reais que as pessoas desfrutam. $\mathrm{O}$ enfoque nas liberdades humanas contrasta com visões mais restritas de desenvolvimento, como as que identificam desenvolvimento com crescimento do Produto Nacional Bruto (PNB), aumento de rendas pessoais, industrialização, avanço tecnológico ou modernização social. $\mathrm{O}$ crescimento do PNB ou das rendas individuais obviamente pode ser muito importante como um meio de expandir as liberdades desfrutadas pelos membros da sociedade. Mas as liberdades dependem também de outros determinantes, como as disposições sociais e econômicas (por exemplo, os serviços de educação e saúde) e os direitos civis (por exemplo, a liberdade de participar de discussões e averiguações públicas). De forma análoga, a industrialização, o progresso tecnológico ou a modernização social podem contribuir substancialmente para expandir a liberdade humana, mas ela depende também de outras influências. Se a liberdade é o que o desenvolvimento promove, então existe um argumento fundamental em favor da concentração nesse objetivo abrangente, e não em algum meio especifico ou em alguma lista de instrumentos especialmente escolhida (SEN, 2000, p. 17).

Do mesmo modo, Souza (2005) assevera que, ao se trabalhar com o conceito de desenvolvimento, deve-se atentar para a concepção de autonomia, compreendida como o poder que uma coletividade tem de se reger, através de suas próprias leis. A autonomia tornase, assim, um pilar fundamental do conceito de desenvolvimento. Vejamos as palavras do autor:

\footnotetext{
7 Para alguns economistas, como Lucena (2000), o desenvolvimento é entendido apenas pela instância "econômica", o que os faz lançar mão da expressão "desenvolvimento econômico". Defendemos que compreender o desenvolvimento tomando como referência apenas uma instância é um erro, pois esse conceito, que expressa um processo de busca do bem-estar social coletivo, é multidimensional, perpassando as instâncias social, econômica, política, cultural, territorial etc. O que Lucena (Ibid.) chama de "desenvolvimento econômico", na verdade, deveria ser chamado de "crescimento ou progresso econômico", resguardando, assim, o conceito de desenvolvimento, que é marcado por maior amplitude e complexidade do que os de crescimento e de progresso.
} 
A autonomia constitui [...] a base do desenvolvimento, este encarado como o processo de auto-instituição da sociedade rumo a mais liberdade e menos desigualdade; um processo, não raro doloroso, mas fértil, de discussão livre e racional por parte de cada um dos membros da coletividade acerca do sentido e dos fins do viver em sociedade, dos erros e acertos do passado, das metas materiais e espirituais, da verdade e da justiça (Ibid., p. 105-106).

Uma sociedade com autonomia é incompatível com a existência de um poder estatal centralizado e incontestável. Sociedade autônoma é aquela marcada pela existência acentuada do poder da coletividade, buscando lograr, defender e gerir seu território por meio da consideração das necessidades e do bem-estar de todos, sem exceção.

Portanto, todas essas concepções destacadas nos conduzem a defender que o desenvolvimento é um processo que envolve satisfação das necessidades coletivas (sociais, econômicas, políticas, culturais etc.), no qual todos os homens têm possibilidade de viver com autonomia e com liberdade, isto é, desprendidos das amarras impostas pelo capital hegemônico. Dessa maneira, é necessário refletirmos se é possível alcançar esse processo no sistema capitalista, o qual tem como fundamento a necessidade das desigualdades, das contradições e das combinações. Em função desse fundamento, acreditamos que desenvolvimento e capitalismo não combinam, ou seja, aquele não é alcançável nesse sistema econômico. Como explicitamos, o máximo que se pode alcançar nesse sistema é a hegemonia econômica da minoria da sociedade, deixando à mercê a grande maioria, isto é, os pobres.

Logo, após as análises realizadas no início desse artigo e em outro trabalho de nossa autoria (SALVADOR, 2010), declaramos que a modernização da agricultura brasileira não vem contribuindo para ou correspondendo ao desenvolvimento da nação. Pelo contrário, esse processo de modernização vem gerando ou agravando problemáticas sociais existentes historicamente no país, sendo que, em contrapartida, pequenos grupos hegemônicos se beneficiam dessa situação, no mínimo, perversa.

Esse pensamento é coadunado por Paulino (2006), quando afirma que o processo de modernização da agricultura brasileira condiz com o progresso de apenas algumas forças produtivas, tendo como inspiração o mercado, cuja finalidade é a acumulação ampliada. Sendo assim, essa autora defende que a modernização em questão gera crescimento econômico e não desenvolvimento ${ }^{8}$.

Com essas abordagens, é imprescindível refletirmos sobre a perversidade da modernização da atividade mandioqueira no Agreste Potiguar. Fazemos isso agora.

\section{O PERVERSO PROCESSO DE MODERNIZAÇÃO DA ATIVIDADE MANDIOQUEIRA NO AGRESTE POTIGUAR}

Acompanhando a perspectiva da modernização da agricultura brasileira, o processo de modernização da atividade mandioqueira no Agreste Potiguar também vem sendo desencadeado de maneira perversa. Esse processo segue meramente os ditames do mercado,

\footnotetext{
8 “[...] convém advertir que o conceito de desenvolvimento, comumente a ela [modernização da agricultura] associado, traz uma imprecisão pouco inocente, porque tomado como sinônimo de crescimento. A menção ao desenvolvimento contempla o progresso social associado à expansão das atividades produtivas, enquanto que o crescimento dimensiona um incremento econômico, via de regra, concentrado. É por isso que se deve proceder às devidas diferenciações, até mesmo para fugir ao lugar comum da crença na neutralidade dos conceitos" (PAULINO, 2006, p. 16).
} 
ancorando-se no aumento de produção e de produtividade, desconsiderando qualquer aspecto relacionado ao bem-estar social coletivo dos trabalhadores. Para evidenciar isso, analisaremos a situação precária de vida e de trabalho em que se encontram os produtores de mandioca e os trabalhadores das casas ou das indústrias de farinha do Agreste Potiguar, que, juntos, constituem a maioria dos agentes da atividade em estudo.

No que se refere aos produtores de mandioca, podemos afirmar que aqueles que são proprietários de terras desencadeiam suas plantações em pequenas propriedades, com área de menos de 10 até 30 hectares, que, muitas vezes, não proporcionam que eles cultivem mais produtos e gêneros alimentícios ou criem mais animais para garantirem suas subsistências e rendas.

Há muitos produtores que não têm propriedades, os quais, juntamente aos que detêm propriedades muito pequenas (de menos de 10 hectares), procuram arrendar pequenas faixas de terra (em torno de 5 a 10 hectares) sob o regime de meação para ter a possibilidade de aumentar sua produção destinada ao provimento de suas rendas e de suas subsistências. Quando arrendam terras, esses produtores são, geralmente, impedidos de cultivar determinadas plantas, como a mandioca, por essas terem períodos de cultivo demorados e, assim, não possibilitarem lucratividade imediata para os detentores das terras. Dessa maneira, os produtores ficam subordinados aos interesses dos donos das terras, tendo-lhes que entregar, no final do arrendamento, metade do que produziram. São agricultores que vivem, portanto, sem a total liberdade de plantar o que pretendem e que, acima de tudo, têm metade dos frutos de seu trabalho explorados por agentes hegemônicos.

Mas os produtores de mandioca não se encontram subordinados apenas aos interesses dos proprietários de maiores áreas de terras do Agreste Potiguar. Esses agricultores também se encontram submetidos aos ditames dos compradores de mandioca (intermediários e donos de casas ou de indústrias de farinha), que exigem que a mandioca seja cultivada com a utilização de adubos e/ou de insumos (venenos, sobretudo) químicos, com alta rentabilidade e no menor tempo possível. Isso faz com que os produtores tenham altos gastos com o cultivo dessa planta, já que têm de lançar mão de quantias consideráveis para a compra desses adubos e insumos, assim como para pagamento do aluguel de tratores para efetuarem rapidamente o preparo da terra para o plantio.

Durante o processo de cultivo da mandioca, vemos, então, que os produtores gastam valores consideráveis, diante de suas precárias realidades, com a aquisição de serviços e de produtos exigidos pelos compradores da mandioca. No final desse processo, os compradores vão aos roçados dos produtores e lhes pagam valores baixíssimos por suas produções. Alguns produtores resistem a esses valores, mas logo percebem que há um cartel quanto ao preço da mandioca e, assim, que não têm outra opção, senão vender sua produção pelo preço ditado pelos compradores.

Os preços pagos são tão baixos e irregulares que, segundo os produtores, por várias vezes, eles têm prejuízo no final do cultivo. Ao conversarmos com o Presidente do Sindicato dos Trabalhadores Rurais de Bom Jesus, tivemos o conhecimento que, num determinado ano, da primeira década do século XXI, o quilo da mandioca foi comprado aos produtores por $\mathrm{R} \$$ 0,03 . Isso significa que para comprar um pão o produtor teria que vender no mínimo quatro quilos de mandioca. 
Mas por que os preços pagos pela mandioca são tão baixos e tão irregulares? A partir das leituras que fizemos e da pesquisa de campo ${ }^{9}$ que desencadeamos, podemos dizer que isso se deve à negligência do Estado brasileiro com o setor mandioqueiro, deixando as indústrias comandarem livremente esse setor, conforme seus objetivos e suas necessidades. Comprovamos na pesquisa de campo a concepção encontrada no livro de Michels, Carvalho e Mendonça (2004), de que os preços pagos no setor mandioqueiro são determinados a partir dos interesses das indústrias de fécula do Centro-Sul nacional, no momento em que chegamos numa indústria de farinha de Vera Cruz e nos deparamos com e-mails mandados pelo Serviço Nacional de Apoio às Micro e Pequenas Empresas (SEBRAE) a seu proprietário, trazendo informações sobre o preço que estava sendo pago "no mercado do Sul-Sudeste" pela mandioca e pela farinha. Diante desses preços, esse industrial formula os preços que ele vai pagar aos produtores agrestinos, influenciando os outros industriais e intermediários que atuam no Agreste Potiguar, propagando interesses externos ao território, mais precisamente provenientes das grandes fecularias do Centro-Sul do país.

Sendo assim, fica explicitada a urgência do Estado brasileiro atentar para o setor mandioqueiro, especificamente para a formação de cartéis nos preços da mandioca e da farinha, buscando considerar, por meio de suas ações, os interesses e as necessidades dos produtores e não meramente dos industriais.

Diante dessa situação de subordinação dos produtores de mandioca do Agreste Potiguar, os poderes públicos federal, estadual e municipal lhes oferecem apoios e/ou ajudas que não vêm sendo eficazes para alterar essa situação vivenciada por esses agentes. Esses apoios constituem-se: em empréstimos de pequenos valores de dinheiro, os quais, muitas vezes, são liberados com grandes atrasos, para a compra de um animal ou para o custeio da mandioca num determinado ano; em algumas horas de trator, fornecidas apenas em alguns anos para a realização do preparo da terra para o plantio; em sementes distribuídas não frequentemente; dentre outras medidas paliativas que, ao invés de alterarem a perversa estrutura vivenciada pelos produtores, as intensificam cada vez mais.

Dessa forma, dizemos que os produtores de mandioca do Agreste Potiguar sobrevivem precariamente no atual contexto de modernização da atividade (figura 02). Esses agricultores vivem, quase na totalidade dos casos encontrados na pesquisa de campo, em graves situações de pobreza, sem acesso à educação, à saúde, ao lazer, por vezes, a no mínimo três alimentações (café da manhã, almoço e janta) durante todo o decorrer do dia etc. Muitas vezes, esses agentes desistem de tentar sobreviver por meio da agricultura, migrando para as cidades do Agreste, onde vão continuar a viver precariamente, muitos por meio de pequenas atividades comerciais, instaladas em suas próprias moradias, fazendo parte, assim, da imensa população urbana que trabalha em atividades do circuito inferior (SANTOS, 2008c).

\footnotetext{
${ }^{9}$ A pesquisa de campo foi realizada, numa perspectiva qualitativa, entre os anos de 2008 e 2010, constituindo-se em observações realizadas no espaço agrícola dos municípios do Agreste Potiguar e em entrevistas realizadas junto a produtores de mandioca, proprietários e trabalhadores de casas ou de indústrias de farinha do referido território.
}

HOLOS, Ano 27, Vol. 2 


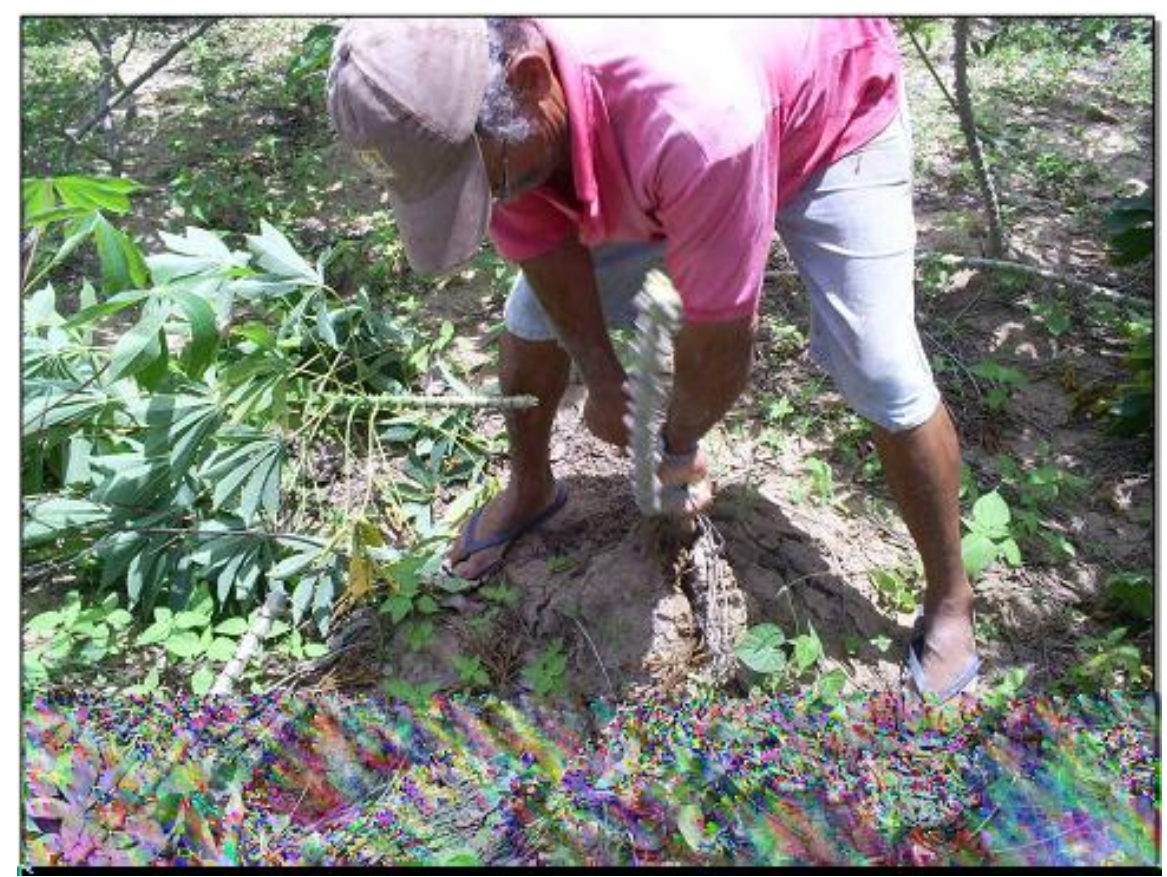

Figura 02: Produtor de mandioca do Agreste Potiguar

Fonte: Pesquisa de campo, 2009.

Quanto aos trabalhadores das casas ou das indústrias de farinha, podemos declarar que estes são submetidos a precárias situações de trabalho. Principalmente nas casas de farinha, em que esses executam funções em ambientes totalmente sem higiene, manuseando instrumentos técnicos sem nenhuma segurança, podendo, a qualquer momento, se acidentarem (figura 03).

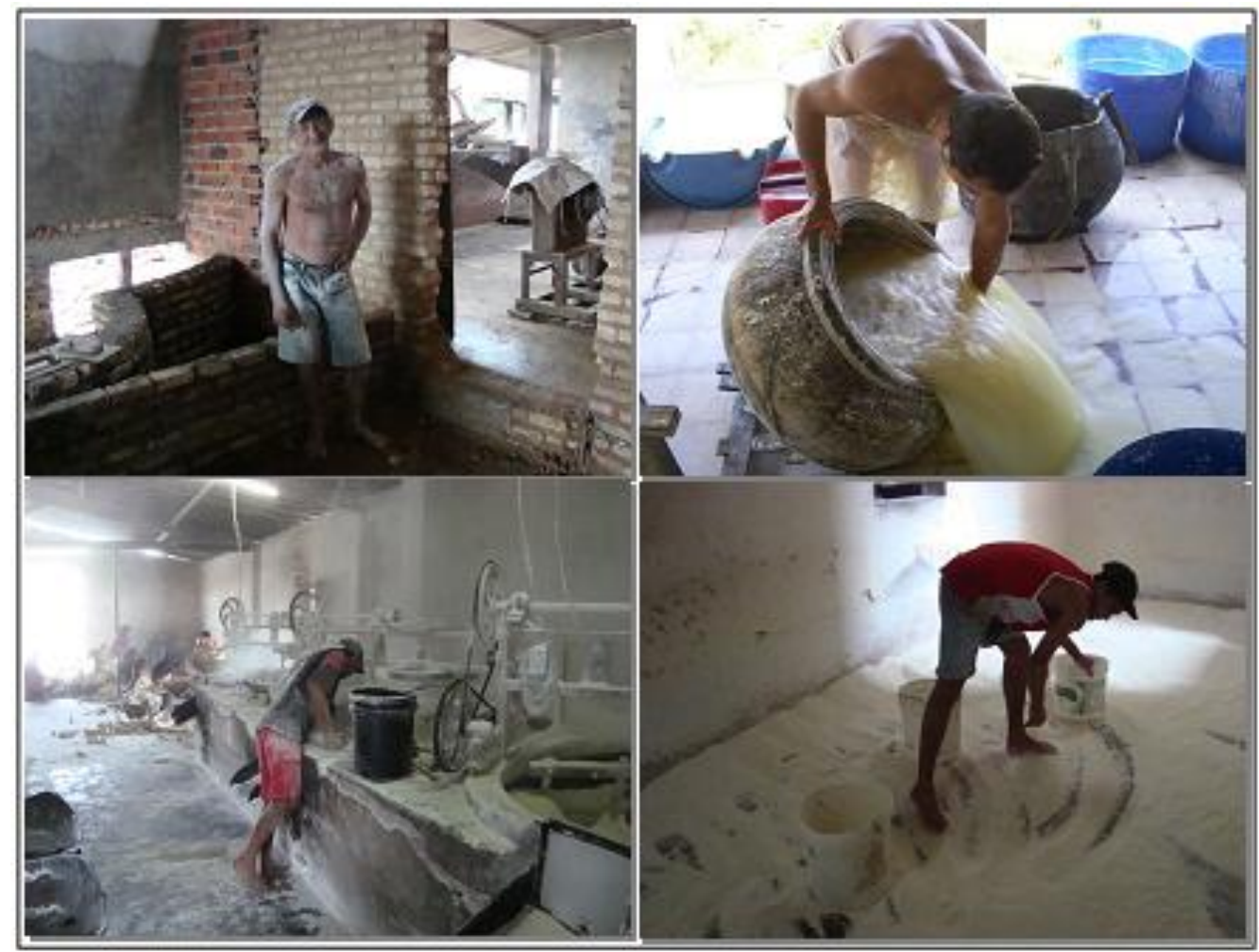

Figura 03: Péssimas condições de trabalho no ambiente das casas de farinha do Agreste Potiguar

Fonte: Pesquisa de campo, 2009. 
As relações de trabalho entre os proprietários e os trabalhadores das casas ou das indústrias de farinha são regidas pela produtividade do trabalho e pelos baixos valores recebidos pelos trabalhadores em relação a suas produtividades. Esses baixos valores fazem com que os trabalhadores se sujeitem a longas e intensas jornadas de trabalho, as quais ultrapassam, comumentemente, as oito horas diárias previstas na legislação trabalhista, visando, com isso, receber valores um pouco maiores pelas funções desempenhadas.

A raspagem da mandioca continua a ser uma função mal remunerada nas casas ou nas indústrias de farinha, sendo deixada, por isso, ao ofício das mulheres. As raspadeiras de mandioca costumam levar a seus locais de trabalho vários de seus parentes (filhos e filhas, irmãs, sobrinhas etc.), para que lhes ajudem a produzir um pouco mais no decorrer de um dia de trabalho. Dentre esses parentes, muitos são menores de idade, sendo alguns crianças de menos de 10 anos, o que nos leva a dizer que o trabalho infantil foi encontrado frequentemente nas casas de farinha do Agreste durante a realização da pesquisa de campo.

Essas constatações nos permitem afirmar, seguramente, que os trabalhadores das casas ou das indústrias de farinha, assim como a maioria dos produtores de mandioca, sobrevivem em situações de trabalho e de vida precárias. Eles são agentes submetidos a contextos marcados pela falta de acesso à educação, à saúde, ao lazer, a alimentações significativas no decorrer do dia, a direitos trabalhistas, por vezes à moradia própria etc. Em suma, são trabalhadores que têm suas forças de trabalho constantemente exploradas, sobrevivendo precariamente no perverso contexto da modernização da atividade mandioqueira.

\section{CONCLUINDO AS DISCUSSÕES}

Por meio da análise da situação em que se encontra a maioria dos trabalhadores da atividade mandioqueira, afirmamos que não é possível defendermos que a modernização dessa atividade venha contribuindo para o desenvolvimento territorial do Agreste Potiguar. Isso devido a esse território estar sendo usado, no âmbito dessa modernização, hegemonicamente por determinados agentes (proprietários das casas ou das indústrias de farinha e intermediários), que propagam e defendem meramente seus próprios interesses e suas próprias necessidades, sem considerar a urgência de se investir no bem-estar social coletivo.

O Agreste Potiguar é na atualidade marcado por graves problemas sociais ${ }^{10}$, como a pobreza da maioria de sua população, que é mostrada em dados estatísticos do Instituto de Desenvolvimento Sustentável e Meio Ambiente do Rio Grande do Norte (IDEMA) (2008) ${ }^{11}$ e do Instituto Brasileiro de Geografia e Estatística (IBGE) (2009), e frisada nas considerações de Costa (2005) e de Gonçalves (2005). No espaço rural desse território, nos deparamos com a precária situação em que vive a grande maioria das pessoas aí residentes, muitas das quais vêm sendo expurgadas para as cidades. Já no espaço urbano, nos deparamos com economias movidas predominantemente por atividades do circuito inferior, o que indica que grande parte

\footnotetext{
${ }^{10}$ Alguns dados estatísticos do IBGE (2009), referentes ao censo demográfico de 2000, trazem à tona a precária situação vivenciada pela maioria dos agrestinos: $35,3 \%$ da população agrestina não era alfabetizada; $86,8 \%$ dos trabalhadores agrestinos tinha renda mensal de menos de 1 a 2 salários mínimos, sendo que, no tocante aos trabalhadores rurais, esse percentual sobe para 92,9\%; e 58,3\% dos trabalhadores exercia funções sem carteira assinada, se sujeitando a situações empregatícias desprovidas de direitos e/ou de garantias previstas na legislação trabalhista nacional.

${ }^{11}$ Esses dados demonstram que aproximadamente $71,57 \%$ da população do Agreste é constituída por pessoas pobres e, destes, aproximadamente $45,48 \%$ podem ser considerados indigentes.
} 
da população urbana também vive em precária situação ${ }^{12}$. Dessa maneira, a pobreza que marca a sociedade agrestina é urbana e rural, sendo negligenciada pelas velhas estruturas políticas que marcam o território, que privilegiam interesses individualistas e imediatistas.

Com isso, uma consideração a ser feita diante das abordagens realizadas neste texto é a de que modernização econômica e desenvolvimento territorial são processos antagônicos no âmbito brasileiro. Isso é totalmente confirmado a partir das análises feitas acerca da modernização da atividade mandioqueira no Agreste Potiguar.

Contudo, essa consideração também nos leva a refletir sobre o seguinte questionamento: o que poderia ser feito para alterar a perversa situação vivenciada pela maioria dos trabalhadores da atividade mandioqueira no Agreste Potiguar?

A resposta que damos, por hora, a essa questão, é calcada nos pensamentos filosóficos de Sartre (1978) e de Arendt (2008, 2006). Segundo esses pensadores, os homens estão condenados a serem livres e a se auto-determinarem, sem precisar viver como marionetes de certos interesses hegemônicos. Para viverem em plena liberdade, os homens precisam lutar, agir, construir suas próprias histórias de acordo com suas necessidades e com seus interesses coletivos.

Portanto, os produtores de mandioca e os trabalhadores das casas e das indústrias de farinha do Agreste Potiguar precisam ter consciência de suas forças enquanto agentes sociais que podem e devem usar o território tendo como pilar fundamental o bem-estar social de todos. É só por meio da luta e da ação que esses agentes conseguirão construir melhores situações para todos, exigindo, para isso, que o poder público represente, de fato, as necessidades prementes de todos os agentes sociais, e que não se apresente, como ocorre atualmente, como o defensor dos interesses de uma minoria hegemônica, que negligencia veementemente o bem-estar social coletivo. Ao contrário, se os trabalhadores da atividade mandioqueira no Agreste Potiguar ficarem amorfos, isto é, inertes diante das precárias situações em que se encontram, infelizmente, essas situações tenderão a se agravar, à medida que o perverso processo de modernização econômica se intensificar.

Seguindo essa perspectiva de pensamento, destacamos as pertinentes concepções de Santos (2007) ao defender que a implementação de um modelo cívico no Brasil perpassa, entre outros elementos, por dois componentes básicos: cultura e território. No tocante à cultura, o citado autor frisa ser premente a definição, por todos os agentes da sociedade brasileira, da civilização que queremos, do modo de vida que desejamos para todos e da visão comum que temos de nossa sociedade e do mundo. A partir dessas definições, explicitaremos se ansiamos por uma sociedade calcada no individualismo ou no bem-estar social coletivo.

Já em relação ao componente territorial, Santos (Ibid.) assevera que este se refere à adequada gestão do território, que proporcione sua instrumentação de forma a assegurar a todos os agentes sociais os bens e os serviços indispensáveis à existência digna de qualquer homem, sem importar a classe social e o lugar onde esteja o indivíduo. Em outras palavras, afirmamos que o componente territorial transcorre pelo uso do território de maneira banal, ou seja, de um modo em que todos encontrem seu lugar, tendo a possibilidade de viverem em situações não precárias. Esse uso do território só será efetivo se o pilar fundamental a ser alcançado for o bem-estar social coletivo.

\footnotetext{
${ }^{12}$ Afirmamos isso devido a Santos (2008c) nos ensinar que o circuito inferior da economia urbana é mantenedor de pobreza.
} 
A realização eficaz do modelo cívico trazido por Santos (2007), tanto na escala nacional quanto na escala do Agreste Potiguar, depende, acima de tudo, das opções e das ações dos agentes sociais, no caso deste trabalho, dos agrestinos. Parafraseando Sartre (1978), pensamos que o homem é, na verdade, seu projeto de vida, sendo extremamente responsável por seus atos. A vida é feita de escolhas. Destarte, cabe aos agrestinos a escolha de permanecerem como estão, vivendo, em sua maioria, precariamente, ou de buscarem novos rumos, novos usos de seu território, prezando pela coletividade e não pela individualidade egoísta. Destarte, Santos (2008a, p. 330) frisa que "[...] se o homem é projeto, como diz Sartre, é o futuro que comanda as ações do presente ${ }^{13}$ ". Portanto, se os agrestinos anseiam por um futuro melhor, para todos, é urgente colocarem em prática, no presente, ações calcadas neste projeto coletivo de vida.

\section{REFERÊNCIAS}

1. ANDRADE, M. C. A questão do território no Brasil. São Paulo: Hucitec, 2004.

2. Agricultura e capitalismo. São Paulo: Livraria Editora Ciências Humanas, 1979.

3. O Nordeste de ontem e de hoje: continuidade e rupturas. In: FELIPE, J. L. (org.) Manuel Correia de Andrade: o geógrafo e o cidadão. Natal: CCHLA-UFRN, 1995. p. 16-25.

4. ARENDT, H. A condição humana. Tradução de Roberto Raposo. Rio de Janeiro: Forense Universitária, 2008.

5. Brasil, 2006.

O que é política? Tradução de Reinaldo Guarany. Rio de Janeiro: Bertrand

6. COSTA, A. A. da. Desenvolvimento local: gestão do território em pequenas cidades do Agreste Potiguar. Sociedade e Território, Natal, v. 17, n. 1-2, jan./dez. 2005.

7. COUTO, E. Modernizações, racionalidades na agricultura e o uso do território: temporalidades e espacialidades no município de Ibiúna (SP). 2007. Dissertação (Mestrado em Geografia) - Universidade de São Paulo, São Paulo.

8. ELIAS, D. Agricultura científica no Brasil: impactos territoriais e sociais. In: SOUZA, M. A. A. de. (org.) Território brasileiro: usos e abusos. Campinas: Edições Territorial, 2003. p. 315-340.

9. ㄴ. O meio técnico-científico-informacional e a reorganização do espaço agrário nacional. In: MARAFON, G. J. ; RUA, J. ; RIBEIRO, M. A. (orgs.) Abordagens teórico-metodológicas em geografia agrária. Rio de Janeiro: EdUERJ, 2007. p. 49-66.

10. GONÇALVES, F. E. Cidades pequenas, grandes problemas: perfil urbano do Agreste Potiguar. 2005. Dissertação (Mestrado em Geografia) - Universidade Federal do Rio Grande do Norte, Natal.

\footnotetext{
13 "Devemos [...] lembrar-nos de que se o real é o verdadeiro, o possível é sempre maior que o real, e o futuro, mais amplo do que o existente. O presente é o real, o atual que se esvai; e sobre ele, como sobre o passado, não temos qualquer força. O futuro é que constitui o domínio da vontade e é sobre ele que devemos centrar o nosso esforço, de modo a tornar possível e eficaz a nossa ação" (SANTOS, 2008b, p. 94).
} 
11. GRAZIANO DA SILVA, J. O desenvolvimento do capitalismo no campo brasileiro e a reforma agrária. In: STÉDILE, J. P. (coord.) A questão agrária na década de 90 . Porto Alegre: Editora da UFRGS, 2004. p. 137-143.

12. Tecnologia e agricultura familiar. Porto Alegre: Editora da UFRGS, 2003.

13. HESPANHOL, A. N. O desenvolvimento do campo no Brasil. In: FERNANDES, B. M. ; MARQUES, M. I. M. ; SUZUKI, J. C. (orgs.) Geografia Agrária: teoria e poder. São Paulo: Editora Expressão Popular, 2007. p. 271-287.

14. INSTITUTO BRASILEIRO DE GEOGRAFIA E ESTATÍSTICA. Sistema IBGE de recuperação automática (SIDRA): Agreste Potiguar. Disponível em: $<$ http://www.sidra. ibge.gov.br/bda/territorio/unit.asp?codunit=6148\&z=t\&o=4\&i=P > . Acesso em: 03 nov. 2009.

15. INSTITUTO DE DESENVOLVIMENTO ECONÔMICO E DO MEIO AMBIENTE DO RIO GRANDE DO NORTE. Perfil dos municípios do Agreste Potiguar. Disponível em: <http://www.rn.gov.br/secretarias/idema/perfil_municipio.asp>. Acesso em: 21 mai. 2008.

16. KAUTSKY, K. A questão agrária. Tradução de C. Iperoig. São Paulo: Proposta Editorial, 1980.

17. LUCENA, R. B. O papel da agricultura no desenvolvimento econômico brasileiro, 1980/1998. 2000. Dissertação (Mestrado em Economia) - Universidade Federal do Rio Grande do Sul, Porto Alegre.

18. MARTINS, J. de S. A sociedade vista do abismo: novos estudos sobre exclusão, pobreza e classes sociais. Petrópolis: Vozes, 2002.

19. MiChELS, I. ; CARVAlHO, M. da C. ; MENDONÇA, C. G. Mandioca. Campo Grande: Editora da UFMS, 2004.

20. MONTENEGRO GÓMEZ, J. R. Desenvolvimento em (des)construção: provocações e questões sobre desenvolvimento e Geografia. In: FERNANDES, B. M. ; MARQUES, M. I. M. ; SUZUKI, J. C. (orgs.) Geografia Agrária: teoria e poder. São Paulo: Editora Expressão Popular, 2007. p. 39-53.

21. OURIQUES, H. R. A dialética da modernidade. Formação, Presidente Prudente, n. 8, p. 165-172, 2001.

22. PAULINO, E. T. Agricultura e tecnificação: notas para um debate. Revista Agrária, São Paulo, n. 4, pp. 03-19, 2006.

23. PEET, R. Imaginários de desenvolvimento. In: In: FERNANDES, B. M. ; MARQUES, M. I. M. ; SUZUKI, J. C. (orgs.) Geografia Agrária: teoria e poder. São Paulo: Editora Expressão Popular, 2007. p. 19-37.

24. PESSOA, Z. S. Agricultura familiar entre a realidade e a possibilidade de geração de emprego e renda. 2003. Dissertação (Mestrado em Ciências Sociais) - Universidade Federal do Rio Grande do Norte, Natal.

25. SALVADOR, D. S. C. O. Das farinhadas à produção para o mercado: a dinâmica da atividade mandioqueira no Agreste Potiguar. 2010. Dissertação (Mestrado em Geografia) - Universidade Federal do Rio Grande do Norte, Natal.

26. SANTOS, M. A natureza do espaço: técnica e tempo, razão e emoção. São Paulo: Editora da Universidade de São Paulo, 2008a.

27. ___ Metamorfoses do espaço habitado. São Paulo: Hucitec, 2008b. 
28. O espaço dividido: os dois circuitos da economia urbana dos países subdesenvolvidos. Tradução de Myrna T. Rego Viana. São Paulo: Editora da Universidade de São Paulo, 2008c.

29. _ _ O espaço do cidadão. São Paulo: Editora da Universidade de São Paulo, 2007.

30. Por uma outra globalização: do pensamento único à consciência universal. Rio de Janeiro: Record, 2003.

31. SARTRE, J. P. O existencialismo é um humanismo. São Paulo: Abril Cultural, 1978.

32. SEN, A. Desenvolvimento como liberdade. Tradução de Laura Teixeira Motta. Revisão técnica de Ricardo Doniselli Mendes. São Paulo: Companhia das Letras, 2000.

33. SOUZA, M. J. L. de. Algumas notas sobre a importância do espaço para o desenvolvimento social. Revista Território, ano II, n. 3, p. 13-35, jul./dez. 1997.

34. . O território: sobre espaço e poder, autonomia e desenvolvimento. In: CASTRO, I. E. de ; GOMES, P. C. da C. ; CORRÊA, R. L. Geografia: conceitos e temas. Rio de Janeiro: Bertrand Brasil, 2005. p. 77-116.

35. THOMAZ JÚNIOR, A. Trabalho e territórios em disputa: algumas considerações. In: PAULINO, E. T. ; FABRINI, J. E. (orgs.) Campesinato e territórios em disputa. São Paulo: Editora Expressão Popular, 2008. p. 327-352. 